\title{
Fifty years air pollution research and policy in the $\mathbf{E U}$
}

\author{
J. G. Kretzschmar \\ VITO, Flemish Institute for Technological Research, Mol, Belgium
}

\begin{abstract}
Despite the fact that air pollution has been observed since Roman times, and thatin past centuries some limited, rather local actions have already been taken, it required several air pollution episodes with serious health impacts before air pollution management really started in a limited number of cities, regions or countries. A noteworthy example is the famous London smog episode in 1952 that triggered a systematic approach locally and in some other European countries. Based on an "air pollution system" approach, some major evolutions and achievements in the EU are highlighted in this paper for the following subsystems: emissions, immissions, air quality guidelines/standards and modelling.

Keywords: air pollution, historical review, research, policy, monitoring, modelling, management.
\end{abstract}

\section{Introduction}

Air pollution, especially in cities, is not at all a new problem. Already in the writings of the Roman philosopher Seneca air pollution appears. Many centuries later, namely in 1661, J. Evelyn [1] mentioned in his "Fumifugium" the influence of industrial emissions on human health, plants and animals, as well as the transboundary exchange of pollutants between England and France. He even suggested remedial actions such as higher chimneys and industrial zones outside the city. Some 200 years later R.A. Smith published a detailed report on the chemical composition of rainwater as a function of the distance to the centre of the city of Manchester. He was also the inventor of the expression "acid rain" in his book [2]. Around the same time the first steps in cleaning flue gases were set too. A more complete review of this is given in "A history of flue gas 
desulphurization systems since 1850", JAPCA, Vol. 27, No.10, 1977. Note, as one illustrative example, that the UK's 1875 Public Health Act contained already a smoke abatement section to try to reduce smoke pollution in urban areas.

Despite this growing awareness and knowledge as a function of time, and due to the continuously increasing urbanization and industrialization, serious, less or more well documented catastrophic air pollution episodes with major health impacts started in 1930 with the smog episode in the Meuse valley in Belgium, followed by "Donora, Pennsylvania 1948", "Poza Rica, Mexico 1950", "London, UK 1952", "New York, US 1953", ... Those accidents triggered large scale ambient air pollution measurements in different cities, regions and countries. Daily measurements of smoke and sulphur dioxide were started in the City of London in 1954 as well as the determination of sulphuric acid, $\mathrm{NO}_{\mathrm{x}}, \mathrm{CO}$ and $\mathrm{CO}_{2}$ during periods of high pollution [3]. In the US the National Air Sampling Network became operational in 1953, and hourly readings of $\mathrm{NO}_{\mathrm{x}}$, hydrocarbons, $\mathrm{CO}, \mathrm{SO}_{2}, \mathrm{O}_{3}$ and particulates were started in 1955 by the Los Angeles Air Pollution Control District. Many European cities and regions followed in the early sixties [4]. Large scale air pollution monitoring, modelling, and management obviously started some 40 to 50 years ago.

\section{The air pollution system}

Before entering into the description of some of the major changes and/or improvements realized over the past decades, it is worthwhile to have a look at the overall air pollution system from the engineering point of view. As shown in figure 1 air pollution problems, and environmental problems in general, are inherent to whatever human activity. Making products, running processes or rendering services always requires an input of energy and mass into a given (sub)system to get a useful output from the same (sub)system. But, between input and output fractions of the input energy and mass are always lost and escape into the environment. That, the use of those products and the final removal at the end of their life as products and processing/servicing equipment, are the origin of whatever manmade pollution.

More specific for the air pollution system, all problems start with the emission of gaseous or solid pollutants from point, line and surface sources. Once in the atmosphere they are transported, dispersed and eventually transformed in the "transmission" subsystem leading finally to ground level concentrations or immissions and wet or dry deposition on surfaces or in water. Via direct pathways - be it during transmission (cloud shine, electromagnetic radiation, noise) or from immission/deposition (ground shine, ingestion, inhalation, skin deposition) - and via indirect pathways (mainly the food chain) people, the ecosystem and all non-living matter risks to be exposed during shorter or longer periods of time. In order to avoid unwanted effects those levels of exposure have to be limited in time and space and for that purpose Air Quality Guidelines (AQG) have to be defined by international organizations such as the World Health Organization (WHO). In an ideal world those levels, below which the risk for effects is rather improbable, should be enforced in all countries, but 
the reality is different. Indeed "socio-economic constraints", being a function of the specific country or even region and (urban) area, make it impossible to switch in one step and immediately from the present polluted situation to the ideal one. Therefore Air Quality Standards (AQS), taking into account the local physical, financial, economic and political constraints, do generally enforce higher air pollution levels (limit or alert values) than the ones in the international air quality guidelines (reference, guide or target values). Lowering ambient levels does of course not happen by only introducing AQSs or AQGs. The only way to realize that is to reduce or eliminate emissions by an emission abatement policy (legal emission limits) and appropriate technologies and means, be it endof-pipe or (preferentially) in-process or at the input. Fortunately more and more regulation and legislation (eco-norms) enter into force at the level of the products and processes we make and use in order to avoid or reduce air pollution from cradle to grave.

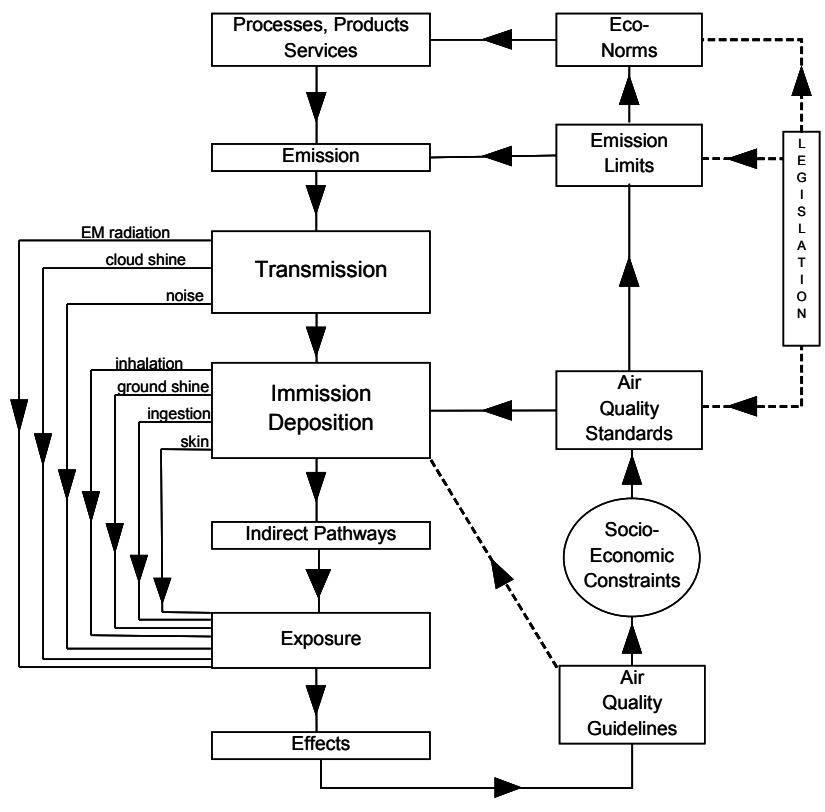

Figure 1: The air pollution system.

Over the past 40 to 50 years major improvements have been realized in each of the subsystems of the overall air pollution system sketched in figure 1 . In what follows the following topics will be highlighted in somewhat more detail with the focus on the European Union Member States: emissions regulated and reduced, ambient air pollutants levels decreased, more stringent AQGs and AQSs, modelling: from nomogram to PC or workstation. 


\section{Emissions regulated and reduced}

As already mentioned in the introduction one of the first actions to curb ambient air pollution levels was to increase chimney heights. In the aftermath of the Great London Smog in 1952 the UK government passed the Clean Air Act 1956 to control industrial sources by the use of tall chimneys. Many other countries took similar actions by imposing formulas or nomograms to calculate the required chimney heights such as the well-known German VDI-2289 Richtlinien in $1963[5,6]$.

But pretty soon people realized that this was not the best solution as whatever mass released in the air must come down somewhere, some day to the earth's surface. Already in the sixties scientists demonstrated the interrelationship between sulphur emissions in continental Europe and the acidification of Scandinavian lakes. The 1972 UN Conference on the Human Environment in Stockholm signaled the start for active international cooperation to combat acidification. This leads in 1979 to the Geneva Convention on Long-range Transboundary Air Pollution, and after much intermediate legislation to the EUdirective 2001/81/EC or NEC-directive [7]. Table 1 summarizes the presently obtained and targeted reductions in acidifying emissions for the EU-15 and two specific countries

Table 1: $\quad$ Emission trends and NEC*-ceilings $2010(\mathrm{kt} / \mathrm{y})$.

\begin{tabular}{|c|c|c|c|c|c|}
\hline & & 1980 & 1990 & 2000 & $2010^{*}$ \\
\hline $\mathrm{SO}_{2}$ & Belgium & 828 & 356 & 172 & 99 \\
& Germany & 7514 & 5326 & 636 & 520 \\
& EU-15 & 26698 & 16500 & 6077 & 3850 \\
\hline $\mathrm{NO}_{\mathrm{x}}$ & Belgium & 442 & 358 & 329 & 176 \\
& Germany & 3334 & 2846 & 1634 & 1051 \\
& EU-15 & 13100 & 13410 & 9931 & 6519 \\
\hline $\mathrm{NH}_{3}$ & Belgium & 89 & 107 & 86 & 74 \\
& Germany & 835 & 736 & 607 & 550 \\
& EU-15 & 3617 & 3634 & 3343 & 3110 \\
\hline
\end{tabular}

Setting global, country specific emission limits for certain pollutants is of course not sufficient to curb the emissions. Emissions have to be specifically regulated for a wide variety of processes and installations and their relevant pollutants. One of the first European countries to do so was Germany with its "Technische Anleitung zur Reinhaltung der Luft" or TA Luft in 1964 with formalized licensing procedures (emission standards, minimum stack height, ambient monitoring) for environmentally relevant plants. Many other countries followed that example by similar regulations. Twenty years later directive $84 / 360 /$ EEC had to start eliminating unequal competition between industries in the Member States due to too large differences between all those national laws. Later on this was refined and extended by the Large Combustion Plants directive (88/609/EEC) and the IPPC directive (96/61/EEC). With respect to industrial 
risk mention must be made of the Seveso directive (96/82/EC), which by the way was approved 20 years after the Seveso disaster on July 10, 1976.

Emissions of mobile sources were somewhat overlooked in the beginning but, following similar regulations in Germany in 1968 and in France 1969, the European Communities issued $\mathrm{CO}$ and hydrocarbon limits for new petrol cars by directive 70/220/EEC and for diesels by directive 72/306/EEC. In the same period $\mathrm{Pb}$ in leaded gasoline was reduced in many countries, or by voluntary actions of the refineries or by legislation. Directive 78/611/EEC harmonized those national initiatives at the EU-level and set the target value at $0,15 \mathrm{~Pb} /$ liter gasoline. Three years earlier something similar had already been done for the sulphur content in liquid fuels by directive 75/716/EEC. Over the years all those limitations became more stringent and led e.g. for lead to directive $85 / 210 / \mathrm{EEC}$ requiring the introduction of unleaded gasoline, not containing more than $5 \%$ benzene (by volume) as of October 1989. The introduction of low emission vehicles, e.g. using 3-way catalytic convertors, was already in 1980 encouraged by tax incentives in West Germany. By directive 88/76/EEC new gasoline vehicles had to be designed to operate with 95 RON unleaded gasoline.

\section{Ambient air pollution levels decreased}

When starting their daily $\mathrm{SO}_{2}$ and smoke measurements in London in 1954, Commins and Waller measured yearly averages of respectively 377 and $160 \mu \mathrm{g} / \mathrm{m}^{3}$ [3]. In the early sixties those levels were still high with values between 438 and 253 for $\mathrm{SO}_{2}$ and 100 to $60 \mu \mathrm{g} / \mathrm{m}^{3}$ for smoke. Daily SO2 extremes were systematically above $1000 \mu \mathrm{g} / \mathrm{m}^{3}$ on a yearly basis, with peak values exceeding $3000 \mu \mathrm{g} / \mathrm{m}^{3}$ as daily averages, and even above $5000 \mu \mathrm{g} / \mathrm{m}^{3}$ on an hourly basis. In other European cities the situation was not much better with the following yearly averages $\left(\mu \mathrm{g} / \mathrm{m}^{3}\right)$ for $\mathrm{SO}_{2}: 250$ in Hamburg, 200 in Paris, 170 for the Ruhr area in Germany, etc... Half-hourly values in Bochum, Germany sometimes exceeded $1 \mathrm{mg} / \mathrm{m}^{3}$ in 1961 [8]. Although the situations ameliorated gradually as a function of time, the early seventies still showed yearly averages clearly above $100 \mu \mathrm{g} \mathrm{SO} / \mathrm{m}^{3}$ and between 50 and $100 \mu \mathrm{g}$ smoke $/ \mathrm{m}^{3}$ in many European urban areas. Very polluted cities were obviously Madrid and Milan [4].

Over the past 40 years ambient $\mathrm{SO}_{2}$ - and smoke - or particulate levels have been drastically reduced and are nowadays in general below the WHO air quality guidelines. This has been realized by much lower sulphur content of liquid fuels, the increased use of sulphur free natural gas, the drastic reduction of coal use, by chances in the industrial processes and by flue gas desulphurization.

The situation for ambient particulate pollution is not all that clear. As long as (black) smoke [9] was measured as indicator for this pollution, a systematically decreasing trend was observed. Taking Antwerpen in Belgium as example $60 \mu \mathrm{g}$ smoke $/ \mathrm{m}^{3}$ was measured as yearly average by the end of the sixties against some $20 \mu \mathrm{g} / \mathrm{m}^{3}$ by the end of the $80 \mathrm{~s}$ and $12 \mu \mathrm{g} / \mathrm{m}^{3}$ in 1995 . But if we switch to PM10, the important particulate pollution indicator since more than 10 years, the same city reports $35 \mu \mathrm{g} / \mathrm{m}^{3}$ for the yearly average in 2005 with more than 
40 exceedances of the daily limit value of $50 \mu \mathrm{g} / \mathrm{m}^{3}$ in the AQS of the EU. This is not exceptional in the EU Member States as is clearly described in [10].

The same reference [10] also shows that after many years of continued efforts, and despite global, but sometimes slow downward trends, the $\mathrm{NO}_{2}$ situation is not completely satisfactory, especially not in busy streets in large urban areas. Indeed at many monitoring stations a number of violations of the $200 \mu \mathrm{g} \mathrm{NO} \mathrm{N}_{2} / \mathrm{m}^{3}$ AQS for half hourly values is still observed today. Even yearly averages did sometimes hardly decrease with for example Paris where the 80 to $90 \mu \mathrm{g} \mathrm{NO} / \mathrm{m}^{3}$ observed in the nineties is still present today. It seems even more difficult to get ambient ozone levels down. Since more than 20 years almost every very good summer period, with stable meteorological conditions, creates $\mathrm{O}_{3}$ problems downwind many urban agglomerations or large industrialized regions. In an European Environment Agency report [11] we read: "In the summer 2005 levels of ground-level ozone were high in southern Europe with widespread exceedances of the information threshold value $\left(180 \mu \mathrm{g} / \mathrm{m}^{3}\right)$ laid down in the ozone directive $(2002 / 3 / \mathrm{EC})$. The frequency of exceedances of the information threshold was similar to earlier years, except for the summer of 2003, which had a record number of exceedances. The highest one-hour ozone concentration in summer $2005\left(361 \mu \mathrm{g} / \mathrm{m}^{3}\right)$ was observed in Portugal. Other high hourly ozone concentrations between 260 and $300 \mu \mathrm{g} / \mathrm{m}^{3}$ were reported from Greece, Italy, France, Romania and Spain. The directive's long-term objective to protect human health, an ozone concentration of $120 \mu \mathrm{g} / \mathrm{m}^{3}$ over 8 hours, was extensively exceeded in the EU and other European countries. In large parts of Europe the target value to protect human health was also exceeded."

Some other harmful pollutants seem nevertheless largely under control after many years of action. Lead in urban streets is for instance one example. Indeed yearly average levels measured today in busy streets of urban agglomerations are in the range $20 \mathrm{ng} / \mathrm{m}^{3}$ while 30 years ago $4 \mu \mathrm{g} \mathrm{Pb} / \mathrm{m}^{3}$ was not a really surprising value. Even around lead smelters the situation improved drastically, although exceedances of the $0,5 \mu \mathrm{g} \mathrm{Pb} / \mathrm{m}^{3}$ yearly average AQS are still possible at a very limited number of monitoring sites. Other examples of ambient air pollutants that significantly decreased over the past decades are: $\mathrm{CO}$ in busy streets, dioxins in the vicinity of specific industrial plants or waste incinerations, benzene and benzo-a-pyrene in cities,... to cite only a few representative examples.

\section{More stringent AQGs and AQSs}

As early as 1959 the World Health Organization (WHO) convened a group of experts to evaluate the possible influence of air pollution on lung cancer. Quite some years later the WHO published in 1972 its first guidelines for $\mathrm{SO}_{2}$ and particulates/smoke in air. Several Env. Health Criteria reports for specific pollutants followed as a function of time, and the original AQGs were regularly updated and extended. A good review of the state of expert knowledge and corresponding AQGs is given in [12]. In the most recent 2005 global update [13] the following AQGs for some priority pollutants are: 
Table 2: $\quad$ Updated WHO a quality guideline values [13].

\begin{tabular}{|c|l|c|}
\hline \multicolumn{1}{|c|}{ Pollutant } & \multicolumn{1}{|c|}{ Averaging time } & AQG value \\
\hline Particulate matter & 1 year & $10 \mu \mathrm{g} / \mathrm{m}^{3}$ \\
$\mathrm{PM}_{2.5}$ & 24 hour (99 ${ }^{\text {th }}$ percentile) & $25 \mu \mathrm{g} / \mathrm{m}^{3}$ \\
& 1 year & $20 \mu \mathrm{g} / \mathrm{m}^{3}$ \\
$\mathrm{PM}_{10}$ & 24 hour (99 ${ }^{\text {th }}$ percentile) & $50 \mu \mathrm{g} / \mathrm{m}^{3}$ \\
\hline Ozone, $\mathrm{O}_{3}$ & 8 hour, daily maximum & $100 \mu \mathrm{g} / \mathrm{m}^{3}$ \\
\hline Nitrogen dioxide, $\mathrm{NO}_{2}$ & 1 year & $40 \mu \mathrm{g} / \mathrm{m}^{3}$ \\
& 1 hour & $200 \mu \mathrm{g} / \mathrm{m}^{3}$ \\
\hline Sulfur dioxide, $\mathrm{SO}_{2}$ & 24 hour & $20 \mu \mathrm{g} / \mathrm{m}^{3}$ \\
& 10 minute & $500 \mu \mathrm{g} / \mathrm{m}^{3}$ \\
\hline
\end{tabular}

One of the first, if not the first set of regional AQSs had already appeared in 1960 in Nordrhein-Westfalen, Germany. The first, legally binding country specific air quality standards were possibly enacted in Japan in 1968. The US followed with its Clean Air Act of 1970, as well as many other countries. In Europe it lasted nevertheless quite some time before certain countries started action. The directive 80/779/EEC of 15 July 1980 on air quality limit values and guide values for sulphur dioxide and suspended particulates was not only the first AQS directive in the EU, but it also forced some of its Member States to finally start action and, for all 9 countries, to bring their national legislation in line with the limit and guide values specified in that directive. Note also that the limit values in 80/779/EEC were significantly higher than the WHO air quality guidelines of those days. As one example: AQG for yearly average and maximum daily concentration for $\mathrm{SO}_{2}$ were respectively 40 to 60 , and 100 to 150 $\mu \mathrm{g} / \mathrm{m}^{3}$ versus AQS limit values of 140 and 250 to $350 \mu \mathrm{g} / \mathrm{m}^{3}$ (as 98-percentile) in the directive.

As can be seen in Table 2 the WHO air quality guidelines obviously became more stringent (= lower ambient levels) for $\mathrm{SO}_{2}$ as a function of time, and this also holds for all other pollutants. AQS have followed that evolution in the successive adaptations of EU and national legislations. In 1996 the European Council published its framework directive 96/62/EC with as aim to define the basic principles of a common strategy to:

- define and establish, by means of daughter directives, objectives for ambient air quality in the Community designed to avoid, prevent or reduce harmful effects on human health and the environment as a whole;

- $\quad$ assess the ambient air quality in Member States on the basis of common methods and criteria;

- $\quad$ obtain adequate information on ambient air quality and ensure that it is made available to the public, inter alia by means of alert thresholds;

- maintain ambient air quality where it is good and improve it in other cases. 
Up to now the following daughter directives, bringing the legal limits of ambient air levels almost completely in line with the present day WHO AQGs [12, 13], and also defining some alarm levels, were published:

- $\quad$ 99/30/EC for $\mathrm{SO}_{2}, \mathrm{NO}_{2}, \mathrm{PM}_{10}$ and $\mathrm{Pb}$;

- $\quad 00 / 69 / \mathrm{EC}$ for $\mathrm{CO}$ and benzene;

- $\quad$ 02/03/EC for $\mathrm{O}_{3}$, and 04/107/EC for As, Cd, Ni, Hg and PAHs.

It can be expected that levels and exposure durations in those directives do change in the future - normally downward for the levels - and that still other ambient pollutants will be regulated.

The driving forces for those monotonically decreasing so-called safe ambient levels are multiple. Possibly the main ones are: better knowledge of the overall air pollution system, increased and more generalized public awareness, improved insight in the health and other effects of air pollution, the ever increasing measuring and monitoring capabilities, the ICT and industrial technology progress and improvements in general.

\section{Modelling: from nomogram to PC and workstation}

The main problem to completely evaluate ambient air pollution in a given area, region or country is the fact that air pollution levels are a function of time and space. Although major developments and progress have already been made for airborne or spaceborne monitoring, trying to simultaneously measure pollutants at ground level as a function of time and space over larger areas, it must be admitted that the obtained information is still largely insufficient. A second problem in ambient air pollution measurements are the costs of intensive and prolonged monitoring. Finally it is not possible by means of measurements to forecast the air pollution evolution as a function of changing meteorological conditions, emissions, legislation, town and country planning, industrial and human activities, ... If we could mathematically simulate the blocks "emission, transmission and immission/deposition" in the air pollution system (Figure 1), what preceeds would become possible in a fast and cheaper way. Atmospheric transport and dispersion modelling is trying to do that since many decades.

Already since the $30 \mathrm{~s}$ concentrations were estimated by means of the equations and dispersion parameters of e.g. O. Sutton and C. Bosanquet. In 1957 Hay and Pasquill presented experimental evidence that the vertical distribution of elevated point releases of particles was related to the standard deviation of the wind elevation angle at the point of release. In the same year H. Cramer derived a diffusion equation incorporating standard deviations of the Gaussian distributions. Values for diffusion parameters based on field tests followed, as well as a method to derive the spread of pollutants from wind fluctuation records. F. Pasquill proposed in 1961 a method for estimating diffusion, when such detailed data were not available, as well as the "stability class" concept. Gifford converted in the same year Pasquill's values of angular spread and height into sigma ${ }_{\mathrm{Y}}$ and sigma $\mathrm{z}$ formulas. In 1970 D. Bruce Turner published his well-known "Workbook of atmospheric dispersion estimates" [14], an excellent manual for, and summary of the atmospheric transport and dispersion knowledge 
at that time, as well the start of the widespread use of bi-Gaussian modelling. Based on the compilation of formulas, graphs and chimney formulas, and the practical examples in Turner's workbook, the scientific community started almost immediately with the transfer of that knowledge to mainframe computers in one way or another. The modelling community was born, and the first NATO/CCMS International Technical Meetings on Air Pollution Modelling and its Application were organized in 1971 under the form of expert panels. In the following years those meetings evolved from panels to workshops to authoritative modelling conferences, with in 2007 the $29^{\text {th }}$ edition.

The Gaussian plume model was the central air pollution model during the sixties and seventies, but in the 70 s the solution of the full diffusion equation got more and more interest from the researchers. The various numerical methods to solve that set of differential equations formed an essential element in the next decades. The first photochemical models appeared in the same period too. Longrange air pollution modelling became an important topic in the early $80 \mathrm{~s}$, and the CEC e.g. started an indirect action research programme on the Safety of Thermal Water Reactors with long-range modelling as a specific topic. After 1985 the output of numerical meteorological models was more and more used as model input (the prognostic approach) i.o. meteorological observations (the diagnostic approach). In the last two decades no real inventions have been made except that models became more complex, tackled a wider variety of problems from very local (street canyons e.g.) to very complex (complicated topography, nested models etc...). All of this was only possible thanks to continuously increasing computer power and capabilities, a better and more detailed knowledge of the atmospheric characteristics, improved emission inventories, etc. For a more detailed historical survey of air pollution models reference is made to some relevant papers in [15]. Today, a wide variety of operational models exists as illustrated by the 113 models on the website of the European Topic Centre on Air and Climate Change (www.eea.europa.eu). Despite all what preceeds it is also true that the Gaussian transport and dispersion approach still forms, in one way or another, the basis of many, country specific regulatory models.

\section{Conclusions}

Major reductions in air pollutant emissions in the EU member states were realized during the past 50 years, resulting in drastic decreases of the ambient levels of many air pollutants. Despite this general improvement certain priority pollutants such as nitrogen oxides are not completely under control, while ambient ozone levels and small particulates are still, and sometimes systematically too high downwind major urban areas or industrial zones. The knowledge of the health impacts of air pollution significantly improved, resulting into lower and better underpinned air quality guidelines. The same holds for EU and national air quality standards and the many emission reduction and abatement regulations. Air pollution monitoring tools and networks became more accurate, sensitive and reliable, and cover today a wide range of specific pollutants or groups of pollutants. Modelling, originally almost manual tools of a 
few experts became operational computer based tools for air pollution evaluation, forecasting and management for whatever air pollution problem. Air pollution monitoring and modelling go hand in hand today as reliable tools. Many problems nevertheless still exist and new ones will certainly appear. All of the above does therefore not mean that further developments and their practical implementation will stop today.

\section{References}

[1] Evelyn, J., Fumifugium, Bedel and Colins, London, 1661.

[2] Smith, R.A., Air and Rain: the beginnings of chemical climatology, Longmans, Green, London, 1872.

[3] Commins, B.T. and Waller, R.E., Observations from a ten-year-study of pollution at a site in the city of London, Atm. Env., Vol. 1, pp. 49-69, 1967.

[4] Concawe, Characteristics of urban air pollution: sulphur dioxide and smoke levels in some European cities, Report 4/76, The Hague, March 1976.

[5] Wippermann, F. and Klug, W., Ein Verfahren zur Bestimmung von Schornsteinmindesthöhen, Int. J. Air and Water Pollution, 1962, Vol. 6, pp. 27-48.

[6] VDI-Richtlinien, Ausbreitung luftfremder Stoffe in der Atmosphäre, Zusammenhang zwischen Emission und Immission, Schornsteinhöhen in ebenem, unbebauten Gelände, VDI2289, Blatt 1, June 1963.

[7] CEC, Directive 2001/81/EC of 23 October 2001 on national emission ceilings for certain atmospheric pollutants, OJ L309/22-30, 27.11.2001.

[8] Buck, M., Zur Durchführung und Auswertung der Messung von Schwefeldioxyd-Immissionen, Staub, 1962, Vol. 22, pp. 193-199.

[9] OECD, Methods of measuring air pollution, Paris, 1964.

[10] EEA, Air pollution at street levels in European cities, EEA Technical report, No 1/2006.

[11] EEA, Air pollution by ozone in Europe in summer 2005, EEA Technical report, No 3/2006.

[12] WHO, Air Quality Guidelines for Europe, $2^{\text {nd }}$ edition, European Series No 91, 2001.

[13] WHO, Air quality guidelines global update 2005, www.who.org.

[14] Turner, D.B., Workbook of atmospheric dispersion estimates, PB-191 482, NTIS, 1970.

[15] AMS, Proceedings of the Millennium NATO/CCMS ITM, Boulder US, May 2000, Sunrise Graphics (MA) 05/00-250. 